\title{
ANÁLISE DE DESEMPENHO E EMISSÕES DE UM MOTOR DO CICLO DE DOIS-TEMPOS COM VÁLVULAS NO CABEÇOTE E INJEÇÃO DIRETA DE COMBUSTÍVEL
}

\author{
Dalla Nora, M. ${ }^{1}$; Donadel, L. R ${ }^{1}$; Sari, R. L' ${ }^{1}$; Martins, M. E. S. ${ }^{1}$; \\ Lanzanova, T. D. M. ${ }^{2}$; Zhao, $\mathrm{H}^{2}$. \\ ${ }^{1}$ Universidade Federal de Santa Maria, Grupo de Pesquisa em Motores (GPMOT), \\ Santa Maria, Brasil \\ ${ }^{2}$ Brunel University London, Centre for Advanced Powertrain and Fuels, Uxbridge, \\ United Kingdom
}

E-mails: mack@gepoc.ufsm.br; I donadel@hotmail.com; rafaellagosari@gmail.com; mario@mecanica.ufsm.br; lanzanova@gmail.com; hua.zhao@brunel.ac.uk

\section{RESUMO}

O conceito downsizing têm sido amplamente utilizado em veículos leves de passageiros para redução do consumo de combustível, dada a diminuição do trabalho de bombeamento e redução das perdas por atrito. Superalimentação de ar, injeção direta de combustível, e sistemas de variação dos instantes de abertura e fechamento de válvulas são empregados nesses motores para obter-se desempenho comparável aos motores de maior volume deslocado. No entanto, reduções extremas de deslocamento volumétrico são limitadas por detonação (knocking) devido às elevadas temperaturas e pressões alcançadas no ciclo, obtendo-se, comumente, reduzido torque em baixas rotações do motor. Nesse contexto, propõe-se a aplicação do ciclo de dois tempos a um motor moderno do ciclo de quatro tempos, dispondo de quatro válvulas, câmara de combustão do tipo pent-roof, superalimentação de ar, e injeção direta de combustível. Como resultado, obteve-se um maior torque, particularmente em baixas rotações, enquanto a pressão no cilindro foi largamente reduzida. $O$ processo de limpeza e enchimento do cilindro (scavenging) foi propiciado por um longo período de cruzamento de válvulas com uma razão de pressão positiva no sentido admissão-exaustão. Injeção direta de combustível foi utilizada para se atenuar o curto-circuito de combustível para a exaustão, o qual é o principal responsável pela baixa eficiência e oneração de emissões nos motores de dois tempos convencionais com portas de admissão e exaustão. Realizou-se um comparativo de desempenho e emissões desse conceito de motor utilizando-se gasolina e etanol, uma vez que o etanol é um combustível renovável e apresenta uma maior tolerância a elevada diluição da mistura por gases queimados (EGR interno), o que é recorrente no ciclo de dois tempos. 


\section{INTRODUÇÃO}

As restrições referentes às emissões de dióxido de carbono $\left(\mathrm{CO}_{2}\right)$ da frota veicular tem impulsionado o desenvolvimento de novas tecnologias aplicadas a motores de combustão interna a fim de diminuir seu consumo de combustível. A União Europeia, por exemplo, tem como meta o limite de $95 \mathrm{~g} / \mathrm{km}$ de $\mathrm{CO}_{2}$ para veículos de passageiros fabricados a partir de 2020 [1]. A partir disso, o conceito downsizing e os sistemas de propulsão híbridos estão ganhando espaço no cenário mundial a fim de adequar veículos a um menor consumo de combustível fóssil [2]. A duplicação dos sistemas de propulsão em veículos híbridos (motor de combustão interna + motor elétrico) exige uma redução de volume e massa destes a fim de reduzir a penalização do consumo de combustível do veículo. Em outras palavras, é exigido uma elevada densidade de potência dos motores de combustão interna para veículos hibridizados.

O conceito downsizing, amplamente consolidado no mercado, apresenta aspectos positivos como a diminuição do consumo de combustível com potência equivalente a motores de maior deslocamento volumétrico. Os ganhos são justificados pelas menores perdas por bombeamento, pois o motor opera constantemente em cargas mais elevadas [3]. Similarmente, a eficiência mecânica do conjunto aumenta na proporção em que as perdas por atrito representam uma fração menor da potência total gerada [4]. Os ganhos em consumo de combustível encontram-se na faixa de $20 \%$ a $30 \%$ para motores superalimentados com metade do deslocamento volumétrico de motores naturalmente aspirados [5][6]. Quando o conceito downsizing é levado ao extremo, como no caso de redução do deslocamento volumétrico acima de $60 \%$ [7], ganhos em economia de combustível são próximos a $40 \%$ em certas condições de operação. No entanto, a contínua operação de motores superalimentados de quatro tempos em cargas elevadas impõe riscos a durabilidade do motor devido à maiores solicitações térmicas e mecânicas [8], principalmente durante a ocorrência de detonação (knocking).

Nesse aspecto, o motor de dois-tempos apresenta vantagens sobre o motor de quatro tempos no que diz respeito ao conceito downsizing. Sua maior frequência de ignição, dada a cada rotação do virabrequim, proporciona elevada densidade de potência por unidade de deslocamento volumétrico $\left(\mathrm{kW} / \mathrm{dm}^{3}\right)$ e também por unidade de massa $(\mathrm{kW} / \mathrm{kg}$ ). Elevado torque em baixas rotações e níveis inferiores de vibração (noise vibration and harshness - NVH) são também obtidos em motores de dois tempos [9].

As vantagens dos motores do ciclo de dois-tempos perdem valor quando relacionadas à arquitetura convencional, com janelas de admissão e descarga incorporadas ao cilindro, de modo que a entrada da mistura ar-combustível é controlada pelo movimento do pistão. Assim, a mistura é exposta a curto-circuito (passagem da mistura não queimada da admissão diretamente para a exaustão) durante o processo de limpeza dos gases queimados e enchimento com carga fresca (scavenging), resultando em elevada emissão de hidrocarbonetos não queimados (UHC) e deterioração do consumo de combustível. 
O problema de curto-circuito da mistura em motores de dois tempos é solucionado pela adoção de injeção direta de combustível na câmara de combustão. Assim, o processo de limpeza dos gases queimados é realizado somente por ar, uma vez que a injeção de combustível ocorre ao fechamento das portas de exaustão. Diversos métodos de injeção de combustível foram propostos neste âmbito, desde convencionais eletroválvulas, amplamente utilizadas em motores de quatro tempos [10], até injetores de baixo custo com assistência por ar comprimido [11][12]. Outro empecilho da utilização de motores dois tempos convencionais é a presença do cárter como método de bombeamento de mistura, de modo que óleo lubrificante precisa ser adicionado em quantidades limitadas à mistura. Além disso, portas de admissão e exaustão apresentarem arestas cortantes, o que aumenta o desgaste dos anéis e reduz a durabilidade dos motores.

Com propósito de solucionar tais problemas, Honda [13], Ricardo [14] e Toyota [15] propuseram a utilização da arquitetura dos motores de quatro tempos contemporâneos ao ciclo de dois tempos, com válvulas no cabeçote e lubrificação forçada de óleo com cárter úmido. O processo de limpeza e enchimento do cilindro ocorre então durante um longo período de cruzamento de válvulas de admissão e escape. Como ambos eventos ocorrem perto do ponto morto inferior, os gases queimados não são expelidos pelo movimento do pistão, mas sim pela razão de pressão existente entre os coletores de admissão e exaustão. Logo, é imprescindível a utilização de sobrealimentadores de ar para garantir o funcionamento deste tipo de motor.

A utilização de etanol como combustível tem vital importância na crescente substituição da matriz energética fóssil, a fim de se reduzir a emissão de gases do efeito estufa [16][17][18]. Além disso, do ponto de vista operacional do motor de combustão interna, o etanol apresenta diversos benefícios, como maior resistência à detonação, maior calor latente de vaporização, composição oxigenada e, portanto, menor formação de material particulado [19]. Sua utilização em motores de dois tempos proporciona também os mesmos benefícios. Além disso, no que tange a maior velocidade de chama laminar do etanol em relação à gasolina, obtém-se uma combustão mais estável mesmo em misturas altamente diluídas por gases queimados não rejeitados no processo de scavenging, também referenciado como EGR interno.

Portanto, com base nas possíveis vantagens que o motor de dois tempos com válvulas no cabeçote tem a oferecer, o presente trabalho explora as características de funcionamento deste tipo de motor por meio de injeção direta de gasolina (G95) e etanol (E100), em cargas e rotação usualmente alcançadas por motores de quatro tempos atuais.

\section{PROCEDIMENTO EXPERIMENTAL}

Os experimentos foram realizados em um motor monocilíndrico de pesquisa, com controle eletrohidráulico independente das válvulas de admissão e descarga, instalado no Centre for Advanced Powertrain and Fuel - Brunel University London. As especificações do motor são listadas na Tabela 1. 
Tabela 1 - Especificações do motor utilizado em testes.

\begin{tabular}{|c|c|c|c|}
\hline Modelo do motor & \multicolumn{3}{|c|}{ Ricardo Hydra Camless Dois/Quatro-tempos } \\
\hline Volume deslocado & \multicolumn{3}{|c|}{$0.35 \mathrm{dm}^{3}$} \\
\hline Diâmetro do cilindro & \multicolumn{3}{|c|}{$81.6 \mathrm{~mm}$} \\
\hline Curso do pistão & \multicolumn{3}{|c|}{$66.9 \mathrm{~mm}$} \\
\hline Razão de compressão & \multicolumn{3}{|c|}{$11.8: 1$} \\
\hline Câmara de combustão & \multicolumn{3}{|c|}{ Pent-roof de quarto válvulas com vela de ignição centra } \\
\hline Combustíveis & \multicolumn{3}{|c|}{ Gasolina comercial RON 95 (UK) e etanol (E100) } \\
\hline Injetor de combustível & \multicolumn{3}{|c|}{ Magneti Marelli solenoide de seis-orifícios } \\
\hline Abertura válvula de exaustão & \multicolumn{3}{|c|}{$120^{\circ} \mathrm{CA}$ ATDC } \\
\hline Abertura da válvula de admissão & \multicolumn{3}{|c|}{$130^{\circ} \mathrm{CA}$ ATDC } \\
\hline Fechamento da válvula de exaustão & \multicolumn{3}{|c|}{$230^{\circ} \mathrm{CA}$ ATDC } \\
\hline Fechamento da válvula de admissão & \multicolumn{3}{|c|}{$240^{\circ} \mathrm{CA}$ ATDC } \\
\hline Lift de válvula & \multicolumn{3}{|c|}{$8.0 \mathrm{~mm}$} \\
\hline \multirow{6}{*}{$\begin{array}{c}\text { Início da injeção } \\
\text { de combustível (BTDC) }\end{array}$} & IMEP & Gasolina & Etanol \\
\hline & $0,2 \mathrm{MPa}$ & $110^{\circ}$ & $120^{\circ}$ \\
\hline & $0,4 \mathrm{MPa}$ & $130^{\circ}$ & $125^{\circ}$ \\
\hline & $0,6 \mathrm{MPa}$ & $120^{\circ}$ & $125^{\circ}$ \\
\hline & $0,8 \mathrm{MPa}$ & $120^{\circ}$ & $130^{\circ}$ \\
\hline & $1,0 \mathrm{MPa}$ & $140^{\circ}$ & $120^{\circ}$ \\
\hline
\end{tabular}

A superalimentação de ar necessária para o funcionamento do motor no ciclo de dois tempos foi obtida a partir de um compressor de palhetas AVL 515, com controle em malha fechada de pressão e temperatura $(300 \pm 5 \mathrm{~K})$. A medição das vazões mássicas de ar e combustível foram realizadas através de medidores Hasting HFM-200 e Endress+Hauser Promass 83A Coriollis Effect, respectivamente. A pressão de combustível medida próximo ao injetor manteve-se em $14.5 \pm 0.5 \mathrm{MPa}$, enquanto sua temperatura foi mantida em $300 \pm 5 \mathrm{~K}$. A pressão no cilindro foi medida com um sensor piezoelétrico Kistler 6061B, enquanto as pressões de admissão e exaustão foram obtidas por meio de dois sensores piezo-resistivo Kistler 4007BA20F e 4007BA5F, respectivamente. Os dados de pressão foram relacionados ao ângulo de virabrequim através de um encoder LeineLinde com 720 pulsos por revolução. Termopares do tipo $\mathrm{K}$ foram utilizados para medição das temperaturas de admissão, exaustão, óleo, e linha de combustível. A medição dos gases de exaustão, como monóxido de carbono (CO), hidrocarbonetos não-queimados (UHC), e óxidos de nitrogênio (NOx) foi realizada por meio de um Horiba MEXA 7170DEGR, enquanto a emissão de soot foi realizada pelo equipamento $A V L 415$ smokemeter. $A$ instrumentação e o esquemático de instalação do motor de pode ser visto na Figura 1. Para todos os testes, a temperatura de óleo lubrificante e fluído de arrefecimento foi mantida em $353 \pm 3 \mathrm{~K}$. Os tempos de ignição e injeção de combustível, assim como os parâmetros de válvulas, foram controlados através de uma unidade Ricardo rCube. A aquisição e processamento de dados em tempo real foi realizada em código próprio empregando uma placa National Instrumental NI US-6353.

Apesar da injeção direta de combustível atenuar o problema de curto-circuito durante o período em que admissão e exaustão coexistem, o risco de curto-circuito de ar é 
sempre presente. A perda de ar fresco para exaustão é um fator significante à medida que este sofre trabalho prévio de compressão (supercharger ou turbocharger), e, portanto, onera a eficiência global do sistema. Para se diminuir a perda de ar fresco e forçar o movimento de tumble reverso, foi modificada a geometria da câmara de combustão com um anteparo de forma a impedir a passagem direta do ar para a exaustão, como visto na Figura 1.
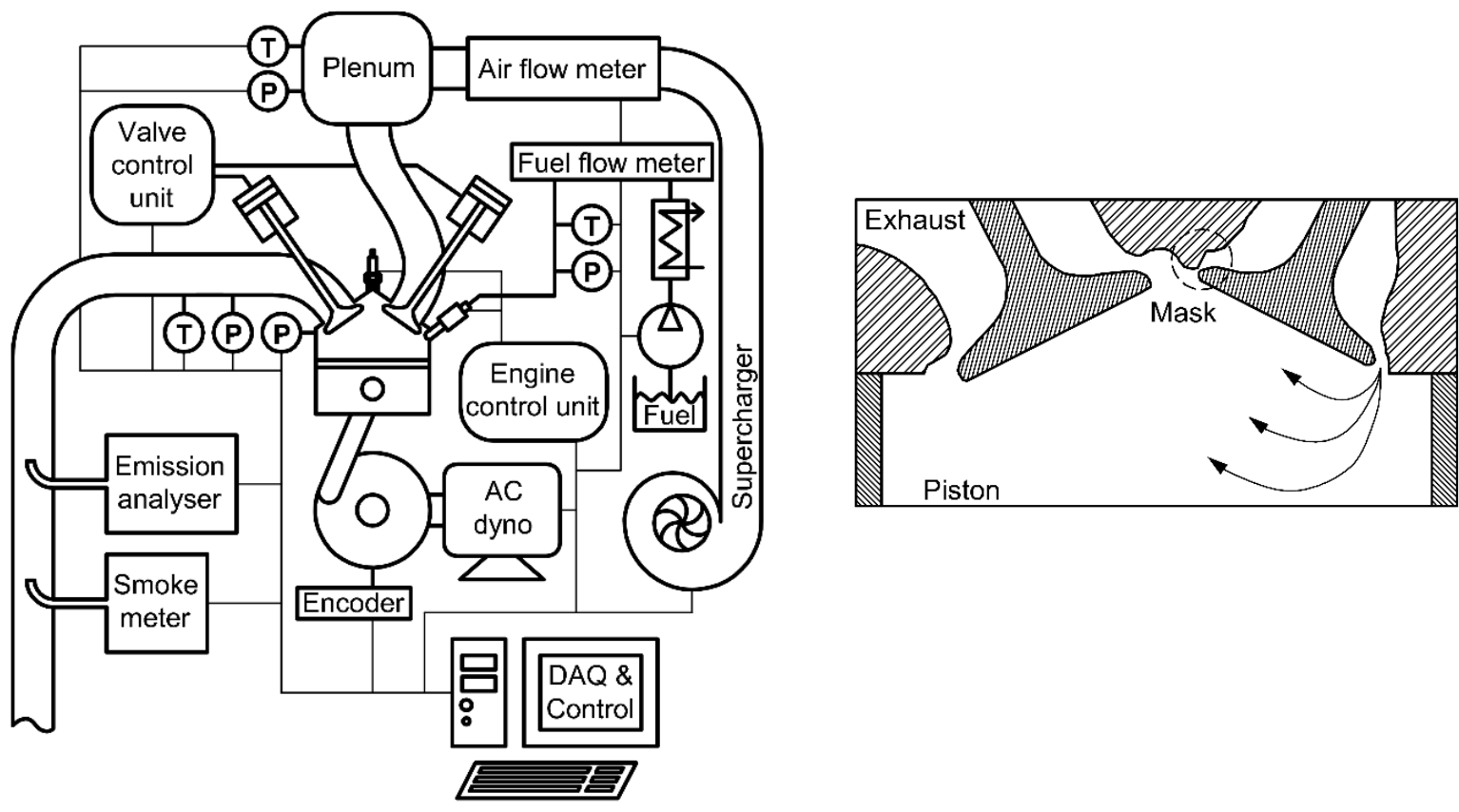

Figura 1 - Instrumentação/aquisição de dados e detalhamento da câmara de combustão.

Realizou-se testes com gasolina e etanol em pressões média efetivas (IMEP) de 0,2 $\mathrm{MPa}$ até $1,0 \mathrm{MPa}$, com incrementos de 0,2 $\mathrm{MPa}$. $\mathrm{O}$ instante de injeção foi investigado para cada combustível e carga, numa faixa de $40^{\circ} \mathrm{CA}$ em torno do fechamento das válvulas de admissão e exaustão. Enquanto a injeção precoce onera o consumo de combustível pela perda deste por curto circuito, a injeção tardia não proporciona boa qualidade de combustão pelo tempo reduzido para homogeneização da mistura. Os momentos de início de injeção estão expostos na Tabela 1. O instante de ignição foi ajustado para o avanço mínimo que possibilitasse máximo torque (MBT), ou limitado por detonação (knocking).

O injetor empregado nesta pesquisa limitou o valor mínimo de IMEP em 0,2 Mpa, pois seu tempo de abertura mínima foi observado em $0,48 \mathrm{~ms}$, o que tornou a combustão excessivamente rica para menores condições de carga. A rotação de operação do motor foi estabelecida em 1600 rpm com base em rotações normalmente alcançadas por motores de quatro tempos em ciclos urbanos cotidianos. Os tempos de abertura e fechamento das válvulas, assim como o lift destas, foram escolhidos com base em estudos prévios [20].

O controle da carga foi realizado pela variação da pressão de admissão de $104 \mathrm{KPa}$ até $155 \mathrm{KPa}$. Devido ao curto-circuito de ar inerente ao processo de scavenging, a 
razão ar/combustível no coletor de exaustão diferiu daquela em que efetivamente ocorreu a combustão. Tal fenômeno é também visível em motores de quatro tempos de elevada performance, onde um longo período de cruzamento de válvulas de

admissão e descarga é requerido. Portanto, para se obter uma razão ar/combustível estequiométrica no coletor de exaustão, seria necessário ter-se uma combustão rica em combustível, resultando em uma redução expressiva da eficiência indicada. Desse modo, optou-se por uma operação que maximizasse a eficiência indicada (lean), mesmo sabendo-se da dificuldade no tratamento dos gases de exaustão em tal regime de mistura ar-combustível. A variabilidade cíclica da combustão limitou o regime lean de combustão, sendo essa expressa pela covariação da pressão média efetiva (COVIMEP). Valores de COVIMEP até $3 \%$ em motores de quatro tempos são toleráveis [21]. Por outro lado, considerando a menor variação de torque em motores de doistempos devido sua maior frequência de ignição dobrada, valores até $6 \%$ foram tolerados neste estudo.

\section{RESULTADOS}

A eficiência indicada para cada condição de operação utilizando-se gasolina e etanol pode ser observada na Figura 2, a qual considera também o trabalho do supercharger (estimado com uma eficiência de $65 \%$ ) no cálculo da potência líquida. Utilizando-se gasolina, atingiu-se eficiências na ordem de 0,31 até 0,33 , enquanto para o etanol observou-se um incremento de até $10 \%$ nas eficiências, estabelecendo-se entre 0,32 até 0,35 . Os valores encontrados são similares e vão ao encontro dos parâmetros encontrados em [22] com um motor de quatro tempos downsized GDI bicilíndrico de $850 \mathrm{~cm}^{3}$ de deslocamento volumétrico.

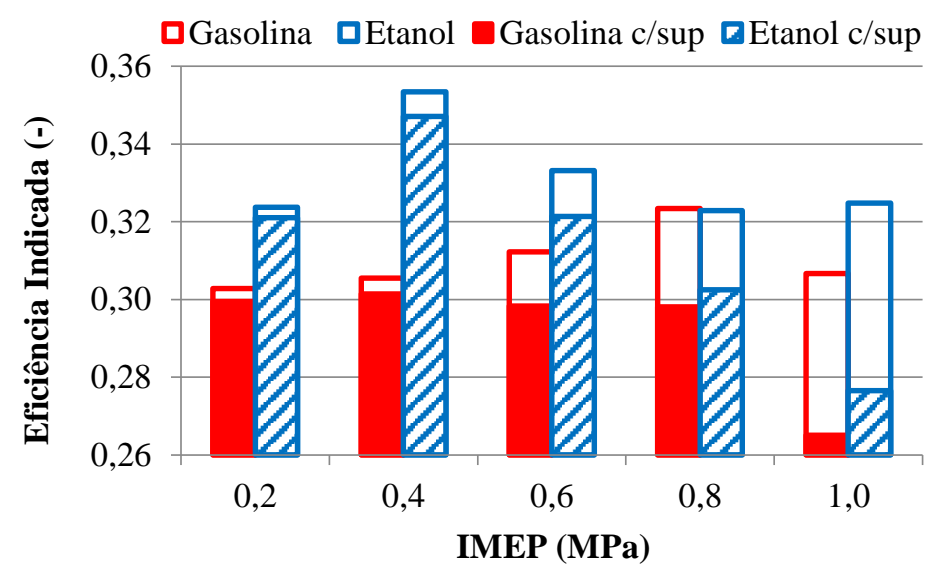

Figura 2 - Eficiência indicada (-) versus IMEP.

A medida que a carga do motor é aumentada, o trabalho consumido pelo supercharger eleva-se em maiores proporções, resultando em menores valores de eficiência indicada líquida. $O$ aumento não linear do trabalho do compressor é consequência das maiores pressões e vazões de ar necessárias para realizar a expulsão dos gases queimados do interior do cilindro, assim como para enchê-lo com ar fresco. 
Para ambos os combustíveis o ponto de inflexão das eficiências líquidas ocorre próximo à pressão média efetiva de $0,4 \mathrm{MPa}$ IMEP. Porém, essa tendência não permanece constante ao se analisar as eficiências brutas, uma vez que para a gasolina o ponto de máximo ocorre em 0,8 Mpa IMEP, enquanto para o etanol este ocorre novamente em $0,4 \mathrm{Mpa}$. Atribui-se tal diferença a quantidade de gás residual presente na câmara de combustão, a qual é menor em cargas elevadas, bem como a maior tolerância do etanol a uma combustão diluída em função de sua composição oxigenada e maior velocidade de chama laminar que a gasolina. Além disso, como pode ser observado na Figura 3, a operação com gasolina foi limitada por detonação a partir de 0,6 MPa IMEP, resultando em avanços de ignição menores e consequentemente uma deterioração da eficiência em comparação ao etanol, com o qual foi possível alcançar MBT em todas as cargas testadas.

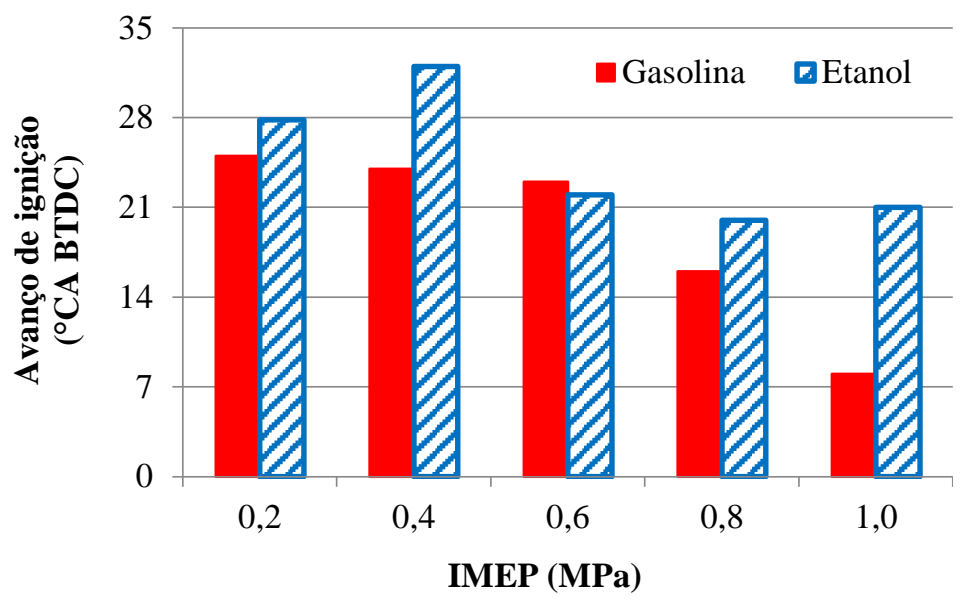

Figura 3 - Avanço de ignição ( ${ }^{\circ} \mathrm{CA}$ BTDC) versus IMEP.

Maiores valores de carga foram alcançados com maiores valores de razão de pressão admissão/exaustão conforme observado na Figura 4. Para os valores de 0,2 $\mathrm{MPa}$ IMEP com gasolina e etanol, pressões de admissão da ordem de 106 - $108 \mathrm{kPa}$ se fizeram necessárias, enquanto a pressão máxima de $154 \mathrm{kPa}$ foi necessária para se alcançar 1,0 MPa IMEP. Para efeito de comparação, um motor do ciclo de quatro tempos teria de operar sob um valor de IMEP da ordem de 2,0 MPa para se obter o mesmo torque aqui adquirido. Não foi observada uma variação significativa da razão de pressão admissão/exaustão quando da comparação de etanol com gasolina, embora o etanol tenha demonstrado uma necessidade de alimentação de ar ligeiramente menor, possivelmente em função de sua formulação oxigenada.

A partir dos valores de pico de pressão no cilindro (Figura 5), é possível observar a vantagem do ciclo de dois tempos sobre o ciclo de quatro tempos. Comparado com motores downsized de quatro tempos operando sob torques semelhantes, é possível obter-se uma redução de até $50 \%$ da pressão máxima nas condições de maior eficiência. As menores pressões internas não só reduzem o estresse estrutural, mas também possibilitam a otimização do phasing de combustão próximo ao MBT. Com isso, é possível a obtenção de maiores eficiências indicadas sem a limitação por detonação. Com a utilização de gasolina, o retardo de ignição necessário para se 
atenuar a detonação resultou em menores pressões máximas no cilindro, particularmente acima de 0,8 MPa IMEP.

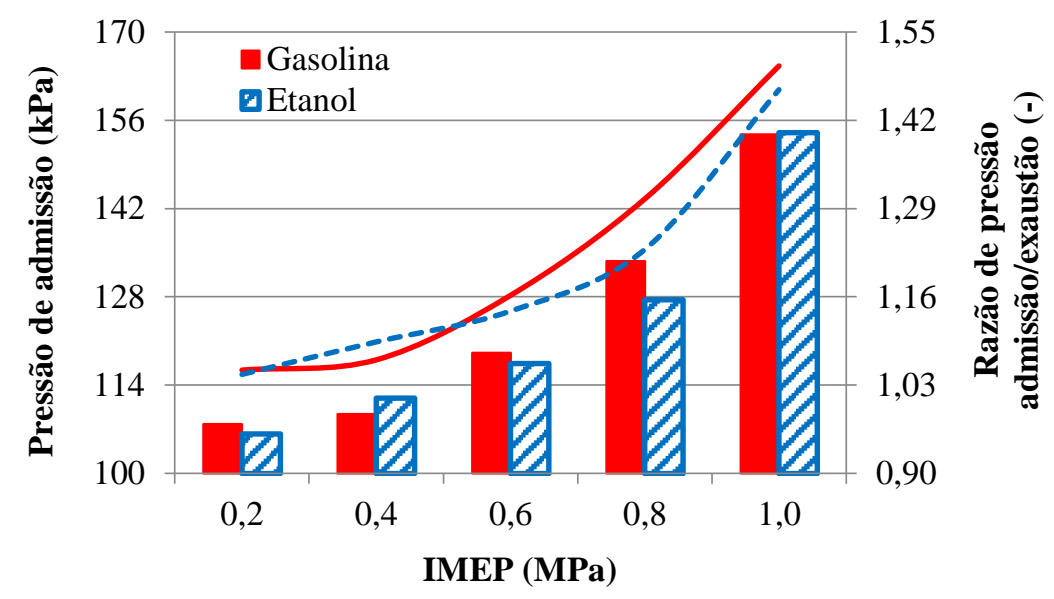

Figura 4 - Pressão de admissão (KPa) e razão de pressão de admissão/exaustão (-) versus IMEP.

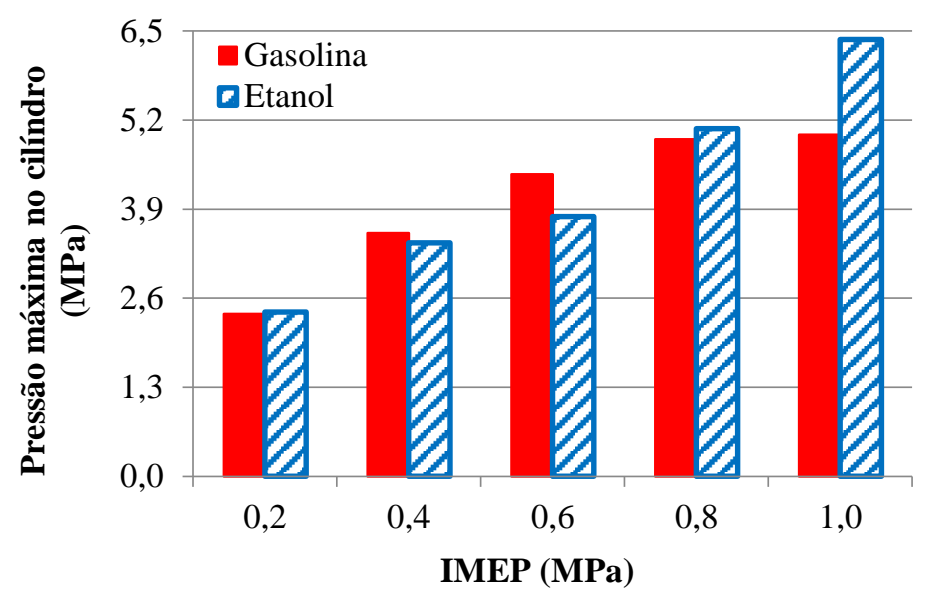

Figura 5 - Pressão máxima no cilindro (MPa) versus IMEP.

A título de comparação com motores do ciclo de quatro tempos, a Figura 6 demonstra a capacidade de obtenção de elevado torque, até $160 \mathrm{Nm} /$ litro, mesmo em baixas rotações como a utilizada nesta pesquisa (1600 rpm). Ressalta-se que para esta condição de operação a pressão no cilindro se manteve inferior a 6,5 MPa.

As menores temperaturas de combustão do etanol dificultaram a total oxidação do $\mathrm{CO}$, resultando em maiores emissões deste como pode ser visualizado na Figura 7. Quanto maior o valor de carga, maiores foram os valores de monóxido de carbono obtidos quando da utilização de etanol. Isto se deu em função da maior estratificação da mistura devido a maiores volumes de combustível injetados em comparação com a utilização de gasolina, dada a diferença de poder calorífico entre os combustíveis. Os instantes de injeção de gasolina para as cargas de 0,8 e 1,0 MPa IMEP ocorreram também antes daqueles empregados para o etanol (Tabela 1), resultando em uma melhor formação de mistura nessas condições. 


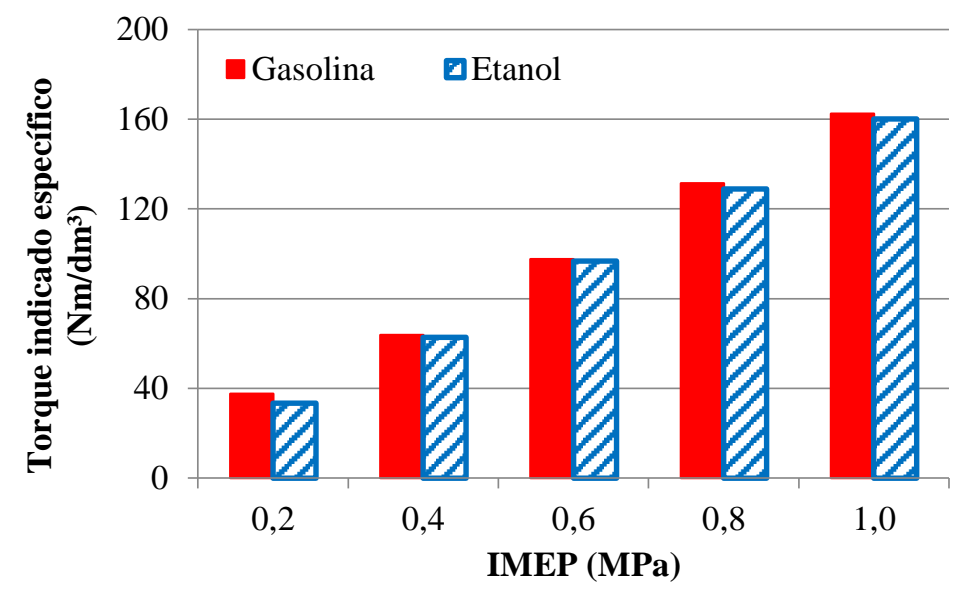

Figura 6 - Torque específico indicado $\left(\mathrm{Nm} / \mathrm{dm}^{3}\right)$ versus IMEP.

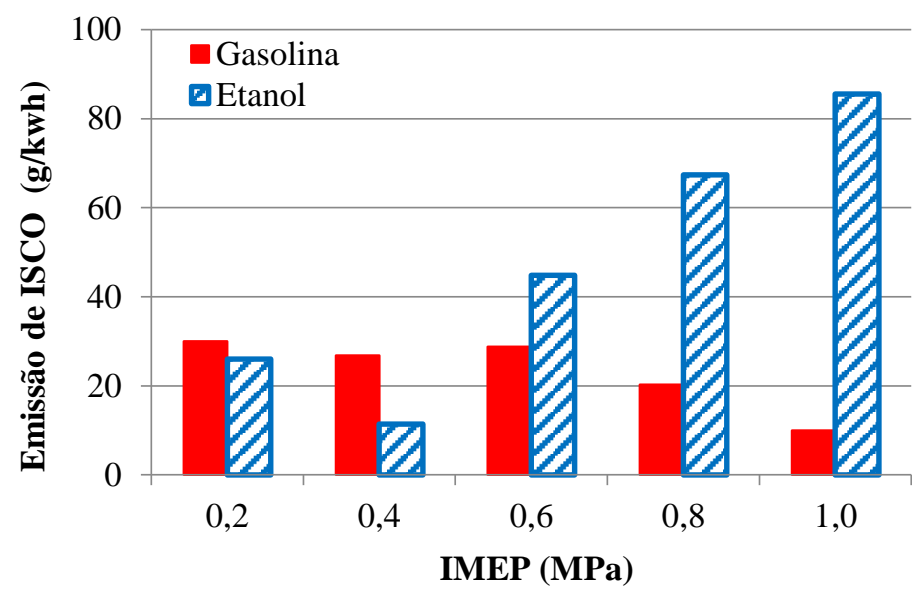

Figura 7 - Emissão de ISCO (g/kwh) versus IMEP.

A utilização de injeção direta de combustível favoreceu a redução de UHC em todas as condições de operação em relação a motores de dois tempos convencionais com a mistura ar-combustível realizada na admissão [23]. A determinação do ponto ótimo de início da injeção de combustível evitou o excessivo curto-circuito de combustível para a exaustão, desse modo atenuando as emissões de UHC como visto na Figura 8. Observa-se, entretanto, a concentração elevada de hidrocarbonetos não queimados nos gases de exaustão a medida que a carga imposta ao motor foi aumentada. Essa tendência deu-se pela pequena fração de combustível em curtocircuito em tais condições, a qual, ainda que não recomendada, se fez necessária para uma melhor homogeneização da mistura ar-combustível. O processo de impingement de combustível sobre as paredes internas da câmara é também uma causa plausível, dada a maior quantidade de combustível injetada. Não foi identificada uma clara diferença nas emissões de UHC quando da utilização de etanol e gasolina

A formação de NOx elevou-se com o incremento da carga devido a maiores temperaturas e menores concentrações de EGR interno, como pode ser visto na Figura 9. A maior disponibilidade de oxigênio em elevadas cargas, em função da maior taxa de limpeza, também favoreceu um incremento nas emissões de NOx. 


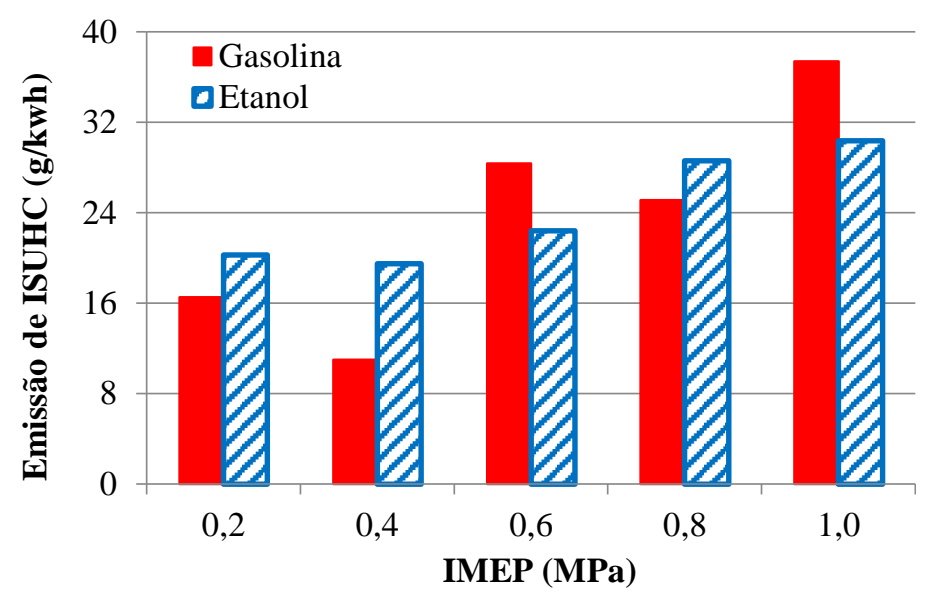

Figura 8 - Emissão de ISUHC (g/Kwh) versus IMEP.

No geral, a soma das concentrações de ISNOx e ISUHC para ambos os combustíveis estão dentro dos valores médios encontrados em motores de quatro tempos. Valores próximos a $25 \mathrm{~g} / \mathrm{Kwh}$ (ISNOx + ISUHC) são relatados para um motor quatro-tempos operando com IMEP entre 0,3 Mpa e 0,7 MPa [24]. A combustão de etanol resultou em menores valores de NOx em comparação a gasolina, particularmente nas condições onde MBT pode ser alcançado com a utilização desta. Para as duas maiores cargas, onde a combustão de gasolina foi limitada por detonação, a combustão defasada resultou em menores temperaturas e, portanto, menores diferenças na emissão de NOx.

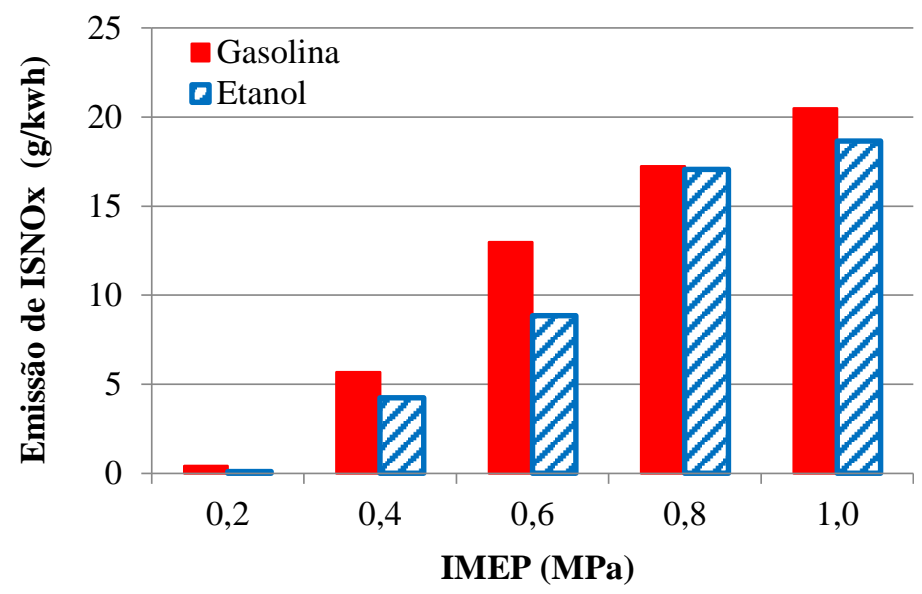

Figura 9 - Emissão de ISNOx ( $\mathrm{g} / \mathrm{Kwh}$ ) versus IMEP.

Em função do curto espaço de tempo disponível para a homogeneização da mistura ar-combustível em decorrência de instantes tardios de injeção, elevadas emissões de soot foram identificadas para a combustão de gasolina. Em cargas elevadas, tais valores são acima mesmo dos limites atualmente impostos a motores Diesel. A relativamente baixa pressão de injeção $(15 \mathrm{MPa})$ é também responsável pela deterioração na formação da mistura, resultando em maior estratificação. A utilização de etanol, entretanto, resultou em emissão nula de soot mesmo em carga máxima. Essa vantagem em sua utilização deve-se a sua composição oxigenada, reduzindo a formação de carbono sólido como pode ser visto na Figura 10. 


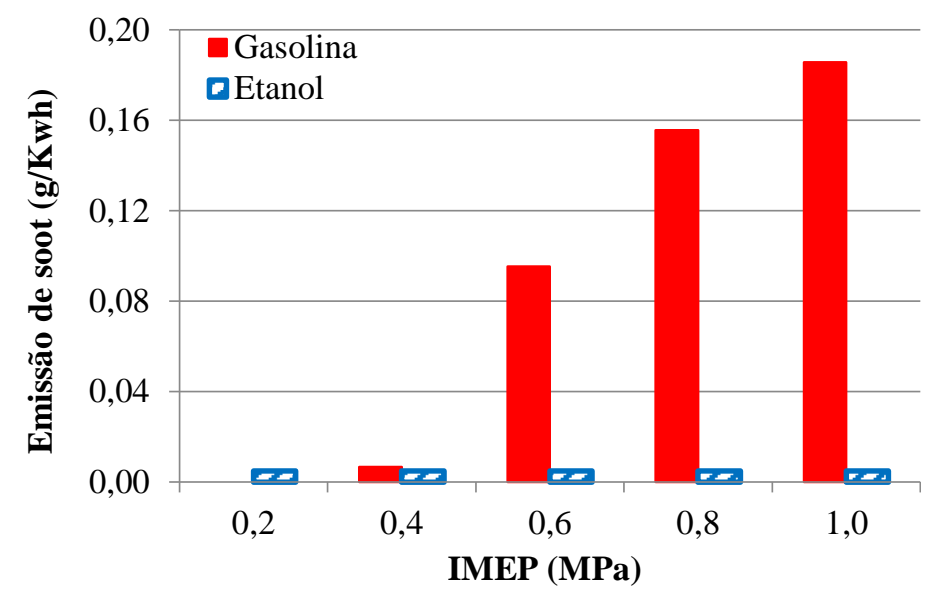

Figura 10 - Emissão de soot (g/Kwh) versus IMEP.

Os resultados para temperatura de exaustão observados na Figura 11 indicam a competição existente entre uma maior liberação de calor da combustão em maiores cargas, e a maior ocorrência de curto-circuito também nessas condições. Quanto maior a carga, maior a demanda por ar, resultando na utilização de maiores pressões de admissão e, portanto, maior curto-circuito de ar. A inversão entre esses dois fenômenos ocorreu próximo a 0,4 MPa IMEP como pode ser observado. A condição de temperatura mínima na exaustão $(535 \mathrm{~K})$ ocorreu na maior carga $(1,0 \mathrm{MPa})$, enquanto a temperatura máxima $(645 \mathrm{~K})$ ocorreu na inflexão mencionada.

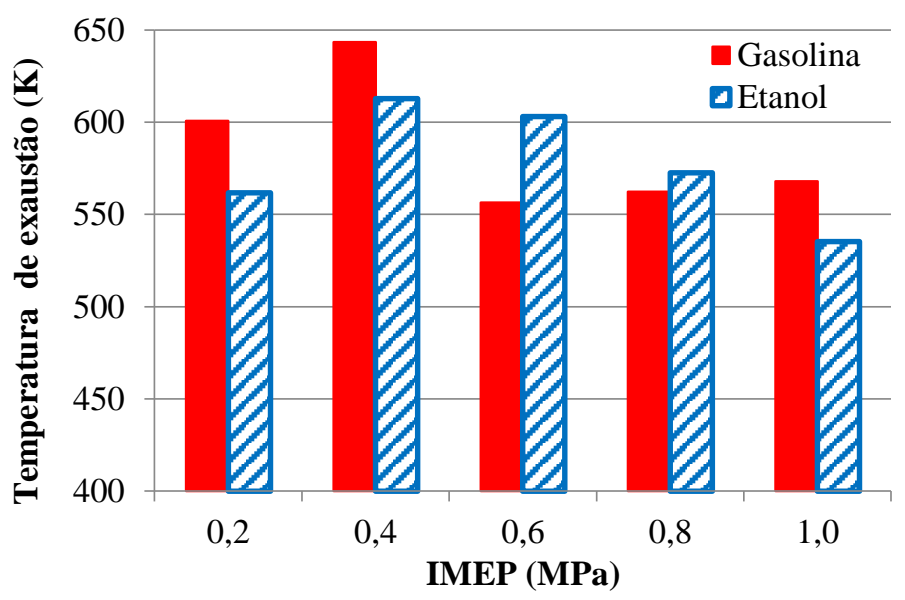

Figura 11 - Temperatura de exaustão $(K)$ versus IMEP.

As baixas temperaturas de exaustão observadas na Figura 11, em comparação àquelas identificadas em motores do ciclo de quatro tempos, representam um empecilho na utilização de conversores catalíticos atuais para redução das emissões de CO, UHC e NOx. Aliado a isso, o curto-circuito de ar eleva a razão ar/combustível dos gases de exaustão, impossibilitando a mitigação de NOx por meio de catalisadores convencionais, largamente difundidos na indústria automotiva. 


\section{CONCLUSÃO}

Nesse trabalho analisou-se o desempenho e emissões de um motor do ciclo de doistempos com válvulas no cabeçote operando com gasolina (G95) e etanol (E100). O emprego da arquitetura moderna dos motores de quatro tempos ao ciclo de dois tempos, com a utilização de uma câmara de combustão pent-roof, sobrealimentação de ar, e injeção direta de combustível, mostrou-se eficaz na superação de alguns problemas inerentes dos motores convencionais do ciclo de dois tempos com portas no cilindro e bombeamento da mistura pelo cárter.

O motor apresentou as melhores eficiências líquidas indicadas com a utilização de etanol. O maior valor registrado de 0,347 ocorreu na pressão média efetiva indicada de 0,4 MPa. No entanto, em uma aplicação prática onde o processo de compressão de ar de admissão possa se dar de maneira mais eficiente, seja via supercharger, turbocharger ou e-charger, maiores valores de eficiência líquida podem ser obtidos.

Elevados valores de torque para a rotação de 1600 rpm foram obtidos em comparação a motores convencionais do ciclo de quatro tempos. Ainda, os valores de pressão no cilindro mostraram-se promissores em comparação aos valores obtidos atualmente nos motores empregados em veículos de passageiros. Menores estresses térmicos e mecânicos propiciam estruturas mais leves e de menor custo, particularmente no que tange a utilização de motores de combustão interna em veículos híbridos.

Enquanto as emissões de $\mathrm{CO}$ e UHC mostraram-se da ordem de grandeza, ou levemente acima daquelas obtidas e motores contemporâneos do ciclo de quatro tempos, os níveis de NOx beneficiaram-se da elevada diluição da mistura por gases queimados remanescentes dos ciclos anteriores. A utilização de etanol resultou em valores inferiores àqueles da gasolina como era esperado, além de eliminar a formação de soot, a qual foi identificada como um sério problema quando da utilização de gasolina.

Por fim, o conceito de motores do ciclo de dois tempos com válvulas no cabeçote mostra-se promissor no que tange a densidade de potência e torque em baixas rotações. No entanto, o processo de conversão catalítica de $\mathrm{CO}$, UHC e NOx apresenta-se como um desafio, particularmente devido ao curto-circuito de ar e, por conseguinte, a baixa temperatura de exaustão e diluição de gás queimado obtidos.

\section{AGRADECIMENTOS}

Os autores agradecem ao Conselho Nacional de Desenvolvimento Científico e Tecnológico (CNPq) pelo auxílio financeiro à pesquisa.

\section{REFERÊNCIAS}

[1] International Council on Clean Transportation (ICCT). EU CO2 emission standards for passenger cars and light-commercial vehicles. 2014. 
[2] SILVA, C; ROSS, M; FARIAS, T. Evaluation of energy consumption, emissions and cost of plug-in hybrid vehicles. Energy Conversion and Management. 2009;50(7):1635-43.

[3] MARTIN S; BEIDL C; MUELLER R. Responsiveness of a 30 Bar BMEP 3Cylinder Engine: Opportunities and Limits of Turbocharged Downsizing. SAE Tech. Pap., 2014. doi:10.4271/2014-01-1646.

[4] HANCOCK D; FRASER N; JEREMY M; SYKES R, BLAXILL H. A New 3 Cylinder 1.2l Advanced Downsizing Technology Demonstrator Engine. SAE Tech. Pap., 2008. doi:10.4271/2008-01-0611

[5] LUMSDEN G; OUDENIJEWEME D; FRASER N; BLAXILL H. Development of a Turbocharged Direct Injection Downsizing Demonstrator Engine. SAE Int J Engines 2009;2:2009-01 - 1503. doi:10.4271/2009-01-1503

[6] EICHHORN A; LEJSEK D; HETTINGER A; KUFFERATH A. Challenge Determining a Combustion System Concept for Downsized SI-engines - Comparison and Evaluation of Several Options for a Boosted 2-cylinder SI-engine. SAE Tech. Pap., 2013. doi:10.4271/2013-01-1730.

[7] TURNER J.W.G; POPPLEWELL A; PATEL R; JOHNSON TR; DARNTON NJ; RICHARDSON S, et al. Ultra Boost for Economy: Extending the Limits of Extreme Engine Downsizing. SAE Int J Engines 2014;7:2014-01 - 1185. doi:10.4271/201401-1185.

[8] ATTARD W.P; TOULSON E; WATSON H; HAMORI F. Abnormal Combustion including Mega Knock in a 60\% Downsized Highly Turbocharged PFI Engine. SAE Tech. Pap., 2010. doi:10.4271/2010-01-1456.

[9] BENAJES J; NOVELLA R; DE LIMA D; TRIBOTTÉ P; QUECHON N; OBERNESSER $P$, et al. Analysis of the combustion process, pollutant emissions and efficiency of an innovative 2-stroke HSDI engine designed for automotive applications. Appl Therm Eng 2013;58:181-93. doi:10.1016/j.applthermaleng.2013.03.050.

[10] ZHANG Y; ZHAO H; OJAPAH M; CAIRNS A. CAI combustion of gasoline and its mixture with ethanol in a 2-stroke poppet valve DI gasoline engine. Fuel 2013;109:661-8. doi:10.1016/j.fuel.2013.03.002.

[11] LEIGHTON S; CEBIS M; SOUTHERN M; AHERN S, HORNER L. The OCP Small Engine Fuel Injection System for Future Two-Stroke Marine Engines. SAE Tech. Pap., 1994. doi:10.4271/941687.

[12] DURET P; MOREAU J-F. Reduction of Pollutant Emissions of the IAPAC TwoStroke Engine with Compressed Air Assisted Fuel Injection. SAE Tech. Pap., 1990. doi:10.4271/900801.

[13] SATO K; UKAWA H; NAKANO M. A Two-Stroke Cycle Gasoline Engine with Poppet Valves in the Cylinder Head - Part II. SAE Tech. Pap., 1992. doi:10.4271/920780.

[14] HUNDLEBY G.E. Development of a Poppet-Valved Two-Stroke Engine - The Flagship Concept. SAE Tech. Pap., 1990. doi:10.4271/900802.

[15] NOMURA K; NAKAMURA N. Development of a new two-stroke engine with poppet-valves: Toyota S-2 engine. In: Duret $P$, editor. A new Gener. two-stroke engines Futur., Paris: Technip; 1993, p. 53-62.

[16] ZHANG Y; ZHAO H; OJAPAH M; CAIRNS A. CAI combustion of gasoline and its mixture with ethanol in a 2-stroke poppet valve DI gasoline engine. Fuel 2013;109:661-8. doi:10.1016/j.fuel.2013.03.002.

[17] SEMENTA P; MARIA VAGLIECO B; CATAPANO F. Thermodynamic and optical characterizations of a high performance GDI engine operating in homogeneous 
and stratified charge mixture conditions fueled with gasoline and bio-ethanol. Fuel 2012;96:204-19. doi:10.1016/j.fuel.2011.12.068.

[18] TURNER D; XU H; CRACKNELL R.F; NATARAJAN V; CHEN X. Combustion performance of bio-ethanol at various blend ratios in a gasoline direct injection engine. Fuel 2011;90:1999-2006. doi:10.1016/j.fuel.2010.12.025.

[19] CAIRNS A; ZHAO H; TODD A; ALEIFERIS P. A study of mechanical variable valve operation with gasoline-alcohol fuels in a spark ignition engine. Fuel 2013;106:802-13. doi:10.1016/j.fuel.2012.10.041.

[20] DALLA NORA M; LANZANOVA T.D.M; ZHAO H. Effects of valve timing, valve lift and exhaust backpressure on performance and gas exchanging of a two-stroke GDI engine with overhead valves. Energy Conversion and Management, Volume 123, 2016, doi: 10.1016/j.enconman.2016.05.059.

[21] ZHAO H. Advanced direct injection combustion engine technologies and development, vol. 1. Cambridge: Woodhead Publishing; 2010, ISBN 9781845693893 [22] EICHHORN A; LEJSEK D; HETTINGER A; KUFFERATH A. Challenge Determining a Combustion System Concept for Downsized SI-engines - Comparison and Evaluation of Several Options for a Boosted 2-cylinder SI-engine. SAE Tech. Pap., 2013. doi:10.4271/2013-01-1730.

[23] BLAIR G.P; Design and simulation of two-stroke engines. Warrendale: Society of Automotive Engineers; 1996.

[24] STONE R. Introduction to internal combustion engines. 4th ed. Basingstoke: Palgrave Macmillan; 2012. 